\title{
Abortion Law awareness and Abortion Services Utilization among reproductive age women of Inarwa municipality of Eastern Nepal
}

\author{
Vijay Kumar Khanal ${ }^{1 *}$ (i), Hari Prasad Ghimire ${ }^{3}$ Meika Bhattachan $^{1}$, Gyanu Nepal', Shyam \\ Sundar Budhathoki ${ }^{1}$,Khem Raj Sharma ${ }^{1}$, Pramendra Prasad Gupta ${ }^{2}$, Paras Kumar Pokharel ${ }^{1}$ \\ ISchool of Public Health and Community Medicine, B.P. Koirala Institute of Health sciences Dharan, Nepal, ${ }^{3}$ Department of Community \\ Medicine Gandaki Medical College Pokhara, Nepal, ²Department of General Practice and Emergency Medicine, \\ B. P. Koirala Institute of Health Sciences, Dharan, Nepal
}

\begin{abstract}
Introduction: Globally, reproductive health and quality of life among female population has been found to be unsatisfactory in developing world. Until 1963, Nepal's 1854 legal code known as MulukiAin was revised numerous times that banned abortion exempting risk of women's life. Enactment of New Abortion Policy from 2003 brought landmark reforms to the women's choice in family planning methods and ended the sufferings of lengthy prison sentences for abortion crimes. This study was conducted to explore the level of awareness about abortion law with regard to health care utilization among women of reproductive age group along with its association with socio-demographic characteristics. Methodology: A cross-sectional study was conducted in March 2014, in Inarwa Municipality among women of reproductive age group ( 16 to 49 years). Convenient sampling was done to collect data from households. Data was entered and analyzed in SPSS 11.5 and presented in tabular form. Chi-square test was used to show association of awareness of abortion law and socio-demographic variables. Results: education, age at first marriage and age at $1^{\text {st }}$ pregnancy was found to be significant ( $p$ value: $<0.005$ ). Conclusion: As media was the most used source of information, more education on awareness of abortion law and health care utilization should be disseminated through this medium.
\end{abstract}

Key words: - Abortion Law, Reproductive health, Utilization

\section{*Corresponding Author}

Dr.Vijay Kumar Khanal

Associate professor

School of Public Health and Community Medicine

B. P. Koirala Institute of Health Sciences, Dharan,Nepal

Email: vijaykhanal75@gmail.com

Submitted: March 1, 2020

Accepted: June 6, 2020

To cite: Khanal VK, Ghimire HP, Bhattachan M, Nepal G, Budhathoki SS, Sharma KR, et al. Abortion Law awareness and Abortion Services Utilization among reproductive age women of Inarwa municipality of Eastern Nepal. JGMC Nepal. 2020;13(1): 32-38 DOI: 10.3126/igmen.v13i1.27900

\section{INTRODUCTION}

Globally, reproductive health and quality of life among female population has been found to be unsatisfactory in developing world. ${ }^{1}$ Estimates of unsafe abortions in 2008 accounted for a death of 47000 worldwide with decline in deaths by 50 in 1990 to 30 in $2008 .^{2}$ About $97 \%$ of all unsafe abortions are in developing countries while $55 \%$ are in Asia (South Central Asia). ${ }^{3}$ It is difficult to extract relevant data regarding unsafe abortion from countries where access to abortion is legally restricted.

Until 1963, Nepal's 1854 legal code known as Muluki Ain was revised numerous times that banned abortion exempting risk of women's life. About $1 / 4^{\text {th }}$ of women were branded as murderers on the basis of pregnancy termination under charges of infanticide and homicide. Most of these victimized women belonged to poor communities and were illiterate, reported to police mostly by their relatives while women from affluent families resorted to neighboring countries like India for abortion practices. ${ }^{4}$ 
Enactment of New Abortion Policy from 2003, brought landmark reforms to the women's choice in family planning methods and ended the sufferings of lengthy prison sentences for abortion related 'crimes' representing Nepal globally as a model for change. ${ }^{5}$

Being a patrilineal country with many patriarchal societies, Nepal bears cultural and social norms where women are restricted to silence and dominance. Premarital pregnancy is considered culturally unacceptable in developing country like Nepal ${ }^{6,7}$ leading to unsafe abortions while bearing a son is considered culturally acceptable irrespective of number of children ${ }^{8,9}$. Preference for son over daughter has led to sex selective abortion despite being charged with imprisonment for such crime. Such practices have led to unsafe abortion which is underreported keeping the lives of these women at stake. ${ }^{10}$

As we embark in Sustainable Development Goal (SDG 20162030), Nepal has experienced a tremendous achievement with decline in Maternal Mortality Rate (MMR) from 1990 (850/100000 Live Births) to 2011(229/100000 Live births). The pillars for the success in decline in MMR in achieving the target for Millennium Development Goal (MDG) 2015 lies not only with the improvement in healthcare services but also with the Amendment of Abortion Law 2002 to certain extent. ${ }^{11}$

The Abortion law has given women liberty with permission of abortion upto 12 weeks of gestation. Under the new policy, which went into effect from 2003, women are permitted abortion for up to 12 weeks of gestation on request and under certain medical/legal conditions thereafter specifications of Nepal's 2002 Abortion Law, pregnancy termination is available under these circumstances: up to 12 weeks' gestation for any indication, by request, up to 18 weeks' gestation in the case of rape or incest, at any time during pregnancy if mental/physical health or life of the pregnant woman is at risk with approval from a medical practitioner, if fetus is deformed and incompatible with life with approval from medical practitioner. Additional considerations includes punishment for sex selective abortion, right of pregnant women to choose or discontinue pregnancy, minors $(<16$ years) with mental incompetence, a consent by legal guardian is a must and only providers certified in safe abortion care are eligible to provide induced abortion services $^{12}$

Nepalese women in patriarchal society are facing many challenges in battling Right to reproductive and Sexual Health $^{5}$. Despite the legalization of abortion law, there lies a challenge of unsafe abortion as a study in 2008 in
Nepal showed that the number of abortions performed by unregistered providers was likely equal to those done by registered providers ${ }^{13}$ indicating that Nepalese women were lacking utilization of health care facilities for safe abortion.This study was conducted to explore the level of awareness about abortion law and to assess the utilization of abortion services among women of reproductive age group.

\section{METHODS}

A cross-sectional study was conducted in Inarwa Municipality of Sunsari district of Eastern Nepal using non-probability convenient sampling based on household sample of reproductive aged women (15-49 years) purposively. Data was collected for a month in March, 2014.

Inarwa Municipality has 6195 population household with 7946 female of reproductive age group 15-49 years. ${ }^{14}$ There are 10 wards in Inarwa Municipality ${ }^{15}$. Among 10 wards, the ward number 1, 2, 7,8, 9 and 10 were randomly selected by lottery method using simple random sampling.

The population of interest were all women of reproductive age group (16-49) years regardless of their marital status at the time of the survey living in the Inarwa Municipality of eastern Nepal.

This Municipality was chosen for a number of reasons. Firstly, the aim of the study was to get a local community's perspective on the research questions so the semi-urban areas of Inarwa were relevant. Secondly, no similar study had previously been conducted in the area. Thirdly, the area was also chosen on the basis of convenience as Inarwa hospital stands as one of the teaching hospital of B.P. Koirala Institute of Health Sciences.

For ethical reasons the age limit was set to 16 years and older as the topic of interest was within the field of sexual and reproductive health and rights, which could be perceived as a culturally sensitive subject for Nepalese female youths. For the survey, a non-probability sampling technique in the form of convenient sampling was used to reach the respondents.

In total, 375 of 391 respondents who were eligible participated in this study: reasons for non- participation were that women were not healthy to participate $(n=6)$, women were busy with household chores $(n=8)$ and women refused $(n=2)$. Sample size calculation was based on the reference taken by study done by Thapa $S$ and Sharma $\mathrm{SK}^{16}$ where $32 \%$ of women were aware about the legalization of abortion law using single proportion 
formula.

Written ethical clearance was taken from institutional review committee of BPKIHS. Informed consent was obtained from each participant prior to interviewing them by signing a consent form. In order to ensure confidentiality, the questionnaires were anonymous, which meant that no names were noted but instead the questionnaire were coded.

Data was coded, entered in excel program and was analyzed by using Statistical Package for Social Sciences (SPSS) software version 11.5. Finally, descriptive data was presented in table and association of knowledge with sociodemographic data was shown by using chi-square test.

\section{RESULTS:}

A total of 375 respondents out of 391 women of reproductive age group (16-49 years) participated in this study. This gave a response rate of $95.91 \%$.

\section{I) Sociodemographic Characteristics}

Majority (65.6\%) of respondents belonged to age group 26-45 years with mean \pm SD:30.75 \pm 7.884 (Min-Max=17-49 years) with $94.9 \%$ of them belonging to Hindu religion. The maximum, $48 \%$ of the respondents had secondary level education. Among the total married women (93.3\%), there were 44 respondents $(13 \%)$ who were married at less than 16 years of age while only 15 (4\%) were married above 24 years with mean age at marriage \pm SD: $17.52 \pm$ 5.649 (Minimum age: 4 years-Maximum age: 29 years). More than half (63.53\%) of married respondents of had 1-2 children while eight respondents $(2.27 \%)$ had more than 5 children. About three-fourth (80.5\%) of the respondents were homemakers by occupation as shown in table 1.

Table 1. Socio-demographic characteristics of women of reproductive age group of Inarwa Municipality, 2014

\begin{tabular}{lcc}
\hline Characteristics & Categories & $\mathbf{n}(\%)$ \\
Age of the respondent (in years) $(\mathrm{n}=375)$ & $26-45$ & $246(65.6)$ \\
& $\geq 46$ & $11(2.9)$ \\
$\qquad$ Mean \pm SD:30.75 \pm 7.884 (Min-Max=17-49 years) & \\
& Hindu & $356(94.9)$ \\
Religion $(\mathrm{n}=375)$ & Muslim & $2(0.5)$ \\
& Kirat & $5(1.3)$ \\
& others & $12(3.2)$
\end{tabular}

\begin{tabular}{|c|c|c|}
\hline \multirow{5}{*}{ Education $(n=375)$} & Illiterate & $55(14.7)$ \\
\hline & Primary & $35(9.3)$ \\
\hline & Secondary & $183(48.8)$ \\
\hline & $\begin{array}{l}\text { Higher Second- } \\
\text { ary }\end{array}$ & $72(19.2)$ \\
\hline & $\begin{array}{l}\text { Above Higher } \\
\text { Secondary }\end{array}$ & $30(8)$ \\
\hline \multirow{3}{*}{ Marital Status $(n=375)$} & Married & 350 (93.3) \\
\hline & Unmarried & $24(6.4)$ \\
\hline & $\begin{array}{l}\text { Divorced/ } \\
\text { Widow }\end{array}$ & $1(0.26)$ \\
\hline \multirow{4}{*}{ Age in years at Marriage $(n=349)$} & $\leq 13$ & $14(4.01)$ \\
\hline & $>13-<16$ & $30(8.6)$ \\
\hline & $16-24$ & $290(83)$ \\
\hline & $>24$ & $15(4)$ \\
\hline \multicolumn{3}{|c|}{ Mean $\pm S D=17.52 \pm 5.649$ (Min-Max $=4-29$ years) } \\
\hline \multirow{4}{*}{ Number of children $(n=349)$} & No children & $31(9.40)$ \\
\hline & 1-2 children & $223(63.53)$ \\
\hline & $3-4$ & $87(24.78)$ \\
\hline & $\geq 5$ & $8(2.27)$ \\
\hline \multirow{5}{*}{ Occupation of respondents $(n=375)$} & Homemaker & $302(80.5)$ \\
\hline & Labour & $3(0.8)$ \\
\hline & business & $25(6.7)$ \\
\hline & Farmer & $43(11.5)$ \\
\hline & others & $2(0.5)$ \\
\hline
\end{tabular}

II) Abortion and Misconceptions

Among the total participants, 345 (92\%) of respondents had an idea about abortion and the most (82.6\%) used source to gather information was found to be mass media as shown in table 2 .. One fourth (25\%) respondents had misconception regarding abortion as a taboo. Out of 93 (25\%) respondents, 82 of them believed it to be a curse.

Table 2. Misconception regarding abortion among women of reproductive age of Inarwa Municipality, 2014

\begin{tabular}{lcc}
\hline Characteristics & Categories & $\mathbf{n ( \% )}$ \\
Idea about abortion $(\mathrm{n}=375)$ & Yes & $345(92)$ \\
& No & $30(8)$ \\
Sources of information about abortion* & Friends/ neighbour & $119(31.7)$ \\
& Mass media & $310(82.6)$ \\
Presence of taboo regarding abortion & Health Professionals & $73(19.46)$ \\
(n=375) & No & $93(25)$ \\
& Curse & $282(75)$ \\
Type of taboo regarding abortion $(\mathrm{n}=93)$ & Karma & $10(11)$ \\
& Others & $1(1)$ \\
\hline
\end{tabular}

\section{*multiple responses}

III) Knowledge Regarding Abortion Law

With regard to abortion, larger proportion (65\%) had knowledge on abortion law. The most well-known condition among 242(65\%) respondents were two under 
which abortion is legal under some grounds in Nepal (81.40\%) and abortion is illegal on basis of sex selection (76.03\%). However, it was found that least knowledge (13.22\%) was regarding abortion legalization upto 18 weeks on rape/incest. Larger proportion (87\%) among 242 respondents reported of self-decision regarding right to abortion, while $6.6 \%$ reported as right of in-laws (Table $3)$.

Table 3. Knowledge regarding abortion law among women of reproductive age of Inarwa Municipality, 2014

\begin{tabular}{|c|c|c|}
\hline Characteristics & Categories & n (\%) \\
\hline & Yes & $242(65)$ \\
\hline \multicolumn{3}{|l|}{ Knowledge regarding abortion law $(n=375)$} \\
\hline & No & $133(35)$ \\
\hline \multicolumn{3}{|l|}{ Specific knowledge regarding abortion law* $(n=242)$} \\
\hline Abortion is legal on some grounds in Nepal & & $197(81.40)$ \\
\hline Abortion is legal upto 12 weeks upon request & & $109(45.04)$ \\
\hline \multicolumn{2}{|c|}{ Abortion is legal if pregnancy poses danger to mothers health } & $134(55.37)$ \\
\hline Abortion is not legal on the basis of sex selection & & $184(76.03)$ \\
\hline Abortion is not legal without the consent of women & & $114(47.10)$ \\
\hline Abortion is legal incase of fetal abnormality & & $146(60.33)$ \\
\hline Abotion is legal upto 18 weeks on rape/incest & & $32(13.22)$ \\
\hline \multirow{4}{*}{$\begin{array}{l}\text { Opinion regarding right to make decision on } \\
\text { abortion } *(n=242)\end{array}$} & Self & $210(87)$ \\
\hline & husband & $180(86.77)$ \\
\hline & In-laws & $16(6.6)$ \\
\hline & Others & $5(2.47)$ \\
\hline
\end{tabular}

*multiple responses

IV) Utilization of Abortion Related Health Services

Out of total respondents, 52 (14\%) had history of abortion and among those respondents, more than half (60\%) had gone to hospitals for abortion.While $24(45 \%)$ had surgical abortion, 19 (36\%) had spontaneous abortion with majority (50\%) belonging to $12-28$ weeks of period of gestation at time of abortion. Reason for abortion was marked as maternal/fetal complications by $28(54 \%)$ respondents and one participant gave the reason as gender preference. Nearly half $(42.3 \%)$ of respondents who underwent abortion had 2 children. These finding have been shown in table 4.
Table.4 Utilization of abortion related health services among women of reproductive age of Inarwa Municipality, 2014

\begin{tabular}{|c|c|c|}
\hline Characteristics & Categories & N (\%) \\
\hline \multirow{2}{*}{ History of Abortion $(n=375)$} & Yes & $52(14)$ \\
\hline & No & $323(86)$ \\
\hline \multirow{3}{*}{ Place of abortion $(n=52)$} & hospital & $31(60)$ \\
\hline & Private clinic & $12(23)$ \\
\hline & others & $9(17)$ \\
\hline \multirow{3}{*}{ Type of abortion $(n=52)$} & medical & $10(19)$ \\
\hline & surgical & $24(45)$ \\
\hline & spontaneous & $19(36)$ \\
\hline \multirow{4}{*}{$\begin{array}{l}\text { Number of children of termination } \\
\text { seekers }(n=52)\end{array}$} & No & $1(1.92)$ \\
\hline & 1 & $10(19.2)$ \\
\hline & 2 & $22(42.3)$ \\
\hline & $\geq 3$ & $18(34.61)$ \\
\hline \multirow{3}{*}{$\begin{array}{l}\text { Period of gestation at time of abortion } \\
(n=52)\end{array}$} & $<12$ weeks & $23(44)$ \\
\hline & $12-28$ weeks & $26(50)$ \\
\hline & $>28$ weeks & $3(6)$ \\
\hline \multirow{5}{*}{ Reason for abortion $(n=52)$} & $\begin{array}{l}\text { Maternal/Fetal } \\
\text { complication }\end{array}$ & $28(54)$ \\
\hline & Unplanned Pregnancy & $15(29)$ \\
\hline & Gender Preferences & $1(2)$ \\
\hline & Financial burden & $1(2)$ \\
\hline & $\begin{array}{l}\text { Others (Limit family } \\
\text { number etc.) }\end{array}$ & $7(13)$ \\
\hline
\end{tabular}

Table 5 shows that education, age at marriage and age at birth of first child were found to be significantly related with the awareness about abortion.

Table 5. Association between having awareness of legal abortion in Nepal and socio-demographic characteristics

\begin{tabular}{|c|c|c|c|c|}
\hline \multirow{2}{*}{ Characteristics } & \multirow{2}{*}{ Categories } & \multicolumn{2}{|c|}{ Abortion law awareness } & \multirow{2}{*}{$\mathrm{p}$-value } \\
\hline & & Yes (\%) & Non (\%) & \\
\hline \multirow[b]{2}{*}{ Age } & $\leq 25$ years & $74(62.7)$ & $44(37.3)$ & \multirow[b]{2}{*}{0.617} \\
\hline & $\geq 26$ years & $168(65.4)$ & $89(34.6)$ & \\
\hline \multirow{2}{*}{ Religion } & Hindu & $230(64.6)$ & $126(35.4)$ & \multirow{2}{*}{0.898} \\
\hline & Others & $12(63.2)$ & $7(36.8)$ & \\
\hline \multirow[b]{2}{*}{ Education } & Illiterate & $15(27.3)$ & $40(72.7)$ & \multirow[b]{2}{*}{$<0.001^{* *}$} \\
\hline & Literate & $227(709)$ & $93(29.1)$ & \\
\hline \multirow{2}{*}{ Occupation of female } & $\begin{array}{l}\text { Home- } \\
\text { maker }\end{array}$ & $193(63.9)$ & $109(36.1)$ & \multirow{2}{*}{0.417} \\
\hline & others & $49(69.0)$ & $22(31.0)$ & \\
\hline \multirow{2}{*}{ Age at $1^{\text {st }}$ marriage } & $\leq 15$ years & $18(40.9)$ & $26(59.1)$ & \multirow{2}{*}{$0.001^{*}$} \\
\hline & $\geq 16$ years & $202(66.2)$ & $103(33.8)$ & \\
\hline \multirow{2}{*}{ Age at birth of $1^{\text {st }}$ child } & $\leq 16$ years & $5(26.3)$ & $14(73.7)$ & \multirow{2}{*}{$<0.001^{* *}$} \\
\hline & $>16$ years & $198(66.2)$ & 101(33.8) & \\
\hline
\end{tabular}

*highly significant ( $\mathrm{p}$ value $<0.01$ ); ** very highly significant $(\mathrm{p}<0.001)$ 


\section{DISCUSSION}

This study was carried out to describe abortion related awareness of law and hospital services utilization among women of reproductive age group (16 to 49 years) of Inarwa Municipality.

This study was conducted in similar setting as Makwanpur district $^{6}$ where the majority (36.4\%) of female participants were of similar age of 26 to 45 years group as in our study (65.6\%). Likewise, a hospital based study in Kathmandu found that the participants belonged to 30-34 years irrespective of their complains and symptoms. ${ }^{17}$ In a study conducted at Kapan VDC, the education among the respondents was found to be Post higher secondary (47\%) which is comparable to our study where the highest level of education was found to be secondary (48.8\%). ${ }^{18}$ It was surprising to see that $4.01 \%$ of respondents in this study were married by 13 years of age and $8.6 \%$ were married before 16 years which can also be seen as a consequence of abortion in studies in India ${ }^{19}$ where $2.6 \%$ were married before 13 years of age and $22.6 \%$ were married before age 16. Another study in Northern Ethiopia showed that by age 15 almost $50 \%$ girls were married..$^{20}$ The legal age for marriage is taken to be 18 years in Nepal for women.

Misconception regarding abortion was seen among 93 (25\%) participants as taboo which is in resonance with studies conducted among marginalized underserved community of 6 districts under FPAN of Nepal ${ }^{21}$ where $23(19.65 \%)$ respondents thought abortion was $\sin$. Mass media (82.6\%) comprised most used source of information in our study while least source of information was friends/ neighbours (31.7\%) which has also been reflected by a study at Nepal Medical College ${ }^{17}$ with friends (6\%) and media (92\%). As abortion is a stigmatized issue in our country though legalization, this might be the reason for neighbours/friends not to be much source of information. However, a contradictory finding has been reported in study in Rupandehi District. ${ }^{22}$

More than half (65\%) of respondents had a knowledge about abortion law with $81.40 \%$ knowing that abortion was legal in our country. In addition, a study done at Kathmandu Marie Stopes clinic $^{23}$ showed that among the abortion seekers 59\% knew that abortion was legal and two most conditions for abortion was mentioned as health status of mother (43.4\%) and incase of rape/incest $(32.2 \%)$. Likewise, a study by Hald SC et al. ${ }^{6}$ showed that knowledge regarding sex selection being illegal was most known condition (89.1\%), a finding that mirrors our study with response of $76.03 \%$.
Nepal like other developing country is a patriarchal country where husbands hold decision making for the family. Such is the case seen even when it comes to reproductive health and right of women even in neighboring country India. ${ }^{24}$ Our study shows that decision for abortion by self and husband is comparatively similar ( $87 \%$ vs $86.77 \%$ ).

History of abortion was given by $3.2 \%$ respondents in a study by Anderson et $\mathrm{al}^{22}$ while our study had a $14 \%$ respondents with history of abortion. The increase in our respondents may be due to the fact of inclusion of women of reproductive age group 16-49 years, as in earlier study the sample included women of 16-24 years only. As one of the most noted reason for pregnancy was maternal and fetal complication (54\%), this might be the reason for most (50\%) termination of pregnancy between 12 -28 weeks of gestation as seen in our study. Unplanned pregnancy that accounted for $29 \%$ of cause was second reason for abortion as compared with other study ${ }^{23}$ where it was first cause for termination accounting for $53.3 \%$ responses. Other reasons for abortion was found to be limiting of family size (13\%) where the respondents were found to larger proportion (42.3\%) of children at the time of survey. Similar study had been conducted in 2001 in urban $\mathrm{Nepal}^{25}$ where the most given reason (34.4\%) for abortion was too many children with most (43\%) of women having 2 children. Such finding is also supported by study in Srilanka. ${ }^{26}$ Among the total respondents who had undergone abortion (52), the reason for gender preference was only seen among 1 participant. There might have been social desirability bias and the respondents might have feared punishment for crime if reported to police as it is illegal. However, preferences for son still exist among the society as son is considered culturally valuable for performing various death rituals and continuing generation.

It was found that there was an association between literacy and awareness on abortion law ( $p$ value $<0.001$ ) which was also seen in similar other studies. ${ }^{23,27}$ Report from national data also highlights that nearly two thirds of women with higher Secondary education and half with secondary education believed that abortion was legal ${ }^{28}$. The reason for better knowledge on abortion law might be the fact of exposure to information on abortion as inclusion of reproductive health in school curriculum. Age at $1^{\text {st }}$ marriage in Nepal was reported by18 years $(55 \%)$ and by 20 years $(70 \%)^{28}$ but in this study age at marriage was found to be among aged $\leq 13$ years(4.01\%).A study reported that with increase in education level there was a gradual decline in early age at marriage. ${ }^{29}$ This might be 
the reason the women who marry above 16 years in our study have better knowledge than the women who resort to marriage at early age of less than 15 years as education engulfs studies related to sexual and reproductive health. This study findings of better abortion law awareness were found more among women who were married and had their first children when they were 16 years and above than those who had early marriages and were pregnant before 16 years of age.

The reasons for this could be the fact that after marriage, women are bound by social responsibilities and has limited independence forcing her to drop out of school as well.

Lack of this knowledge regarding abortion law has made the vulnerable teenagers and youths more prone to unsafe abortion and lesser utilization of healthcare services. ${ }^{30}$

\section{CONCLUSION}

This study highlights the need to focus education on abortion law among illiterate women and females of adolescent age group. The overall awareness level was satisfactory and use of media was effective for dissemination of information. Of total,17\% respondents had got abortion services from others places than the hospital and clinics. So, more campaigning and health education program should be conducted in the community where early marriages are prevalent.

\section{Conflict of interest: None}

\section{REFERENCES}

1. World Health Organization. Strategy to Accelerate Progress towards the Attainment of International Development Goals and Targets Related to Reproductive Health. Reprod Health Matters.2005;13(25):11-8. DOI: 10.1016/S09688080(05)25166-2

2. AhmanE, ShahIH. New estimates and trends regarding unsafe abortion mortality. Int J Gynaecol Obstet. 2011 Nov;115(2):121-6. DOI: 10.1016/j.ijgo.2011.05.027 PMID: 21885049.

3. Samandari G, Wolf M, Basnett I, Hyman A, Andersen K. Implementation of legal abortion in Nepal: a model for rapid scale-up of high-quality care. Reprod Health. BioMed Central Ltd; 2012 Jan;9(1):7DOI: 10.1186/1742-4755-9-7 PMID: 22475782.

4. Shakya G, Kishore S, Bird C, Barak J. Abortion Law Reform in Nepal: Women's right to Life and Health. Reprod Health Matters. 2004;12(24
Supplement):75-84. DOI: $\quad \underline{10.1016 / S 0968-}$ 8080(04)24007-1

5. Center for Research on Environment Health and Population Activities (CREPHA). Post Legalization Challenges and Initiatives To ensure Access To Safe Abortions In Nepal. Reprod Heal Res Policy Br. 2000;(April 2002).

6. Sc H, Da S. A gap between Law and practice: A Community 's Perception of Unmarried Women 's Abortion Options in Nepal. Heal Prospect J Public Heal. 2013;12(2):24-30. DOI:10.3126/hprospect. v12i2.9869

7. Puri M, Lamichhane P, Harken T, Blum M, Harper CC, Darney PD, et al. "Sometimes they used to whisper in our ears " : health care workers ' perceptions of the effects of abortion legalization in Nepal. BMC Public Health. 2012;12:1-9. DOI:10.1186/1471-2458-12297 PMID: 22520231.

8. Stash S. Ideal-family size and Sex-composition Preferences among wives and husbands in Nepal. Stud Fam Plann. 1996;27(2):107-18.DOI: 10.2307/2138138 PMID: 8714308.

9. Frost MD, Puri M, Hinde PRA. Falling sex ratios and emerging evidence of sex-selective abortion in Nepal: evidence from nationally representative survey data. BMJ Open. 2013 Jan;3(5):1-8. DOI:10.1136/ bmjopen-2013-002612 PMID: 23674444.

10. Abrejo FG, Shaikh BT, Rizvi N. "And they kill me, only because I am a girl"...a review of sexselective abortions in South Asia. Eur J Contracept Reprod Health Care. 2009 Feb;14(1):10-6.DOI: 10.1080/13625180802518231 PMID: 19241297

11. Bhandari T, Dangal G. Maternal Mortality : Paradigm Shift in Nepal. NJOG. 2012;7(2):3-8. DOI:10.3126/ njog.v7i2.11132

12. CREPHA, Government of Nepal. National Facilitybased Abortion Study 2006.

13. Sedgh G, Singh S, Henshaw SK, Bankole A. Legal abortion worldwide in 2008: levels and recent trends. Int Perspect Sex Reprod Health. 2011 Jun;37(2):8494.DOI: 10.1363/3708411 PMID: 21757423.

14. Government of Nepal, National Planning Commission, Central Bureau of Statistics. National Population and Housing Census 2011 (Village Development Committee/Municipality). Vol. 06. Kathmandu; 2014.

15. Central Bureau of Statistics. National Population Census 2011Household and Population by sex ward level. Sunsari; 2012. 
16. Thapa S, Sharma SK. Women's awareness of liberalization of abortion law and knowledge of place for obtaining services in Nepal. ASIAPACJ PUBLIC HEALTH. epub2012 DOI: 10.1177/1010539512454165

17. Tuladhar $\mathrm{H}$, Risal A. Level of awareness about legalization of abortion in Nepal: A study at Nepal Medical College Teaching Hospital. J Nepal Med Coll. 2010;12(2):76-80.

18. Kaphle M. Awareness and Utilization of Reproductive Rights Among the Women of Reproductive Age in Kapan VDC , Nepal. J Heal Aliied Sci. 2013;3(1):5-9. DOI: $10.37107 /$ jhas. 42

19. Raj A, Saggurti N, Balaiah D, G Silverman J. Prevalence of child marriage and its effect on fertility and fertility-control outcomes of young women in India: a cross-sectional, observational study. Lancet. 2009;373(9678):1183-9. DOI: 10.1016/S01406736(09)60246-4

20. Hervish A. 2011. Despite Challenges Ending Early Marriage in Ethiopia is Possible. Population Reference Bureau (PRB). Washington DC.

21. Thapa K, Karki Y, Bista K. Myths and Misconceptions about Abortion among Marginalized Underserved Community. J Nepal Med Assoc. 2009;48(176):27680. DOI:10.31729/jnma.353

22. Andersen KL, Khanal RC, Teixeira A, Neupane S, Sharma S, Acre VN, et al. Marital status and abortion among young women in Rupandehi, Nepal. BMC Womens Health. 2015 Jan;15(17):1-9.DOI: 10.1186/ s12905-015-0175-4 PMID: 25783648.

23. Khanal P, Sanjel K, Chalise HN. Knowledge and Practice of Abortion among Women in Nepal. AsiaPacific E- J Heal Soc Sci. 2014;3(1)

24. Sundari Ravindran, TK Balasubramanian P. "Yes"' to Abortion but "'No"' to Sexual Rights: The Paradoxical Reality of Married Women in Rural Tamil Nadu, India. Reprod Health Matters. 2004;12(23):88-99.DOI: 10.1016/S0968-8080(04)23133-0

25. Thapa S, M Padhye S. Induced Abortion in Urban Nepal. Int Fam Plan Perspect. 2001;27(3):144-8.DOI: $\underline{10.2307 / 2673836}$

26. Perera J, Silva T De, Gange H. Knowledge, behaviour and attitudes on induced abortion and family planning among Sri Lankan women seeking termination of pregnancy. Ceylon Med J. 2004;49(1):14-7.DOI: 10.4038/cmj.v49i1.3278 PMID:15255322.

27. Rocca CH, Puri M, Dulal B, Bajracharya L, Harper CC,
Blum M, et al. Unsafe abortion after legalisation in Nepal: a cross-sectional study of women presenting to hospitals. BJOG. 2013 Aug;120(9):1075-83.DOI: 10.1111/1471-0528.12242 PMID: 23574112.

28. Ministry of Health and Population (MOHP) [Nepal], New ERA, and ICF International Inc. 2012. Nepal Demographic and Health Survey 2011,Page:149-52 Kathmandu, Nepal: Ministry of Health and Population, New ERA, and ICF International, Calverton, Maryland.

29. Kim Choe M, Thapa S, Mishra V. Early Marriage and Early Motherhood in Nepal. J Biosoc Sci. 2005 Mar;37(2):143wwwwww-62. DoI: 10.1017/S0021932003006527 PMID: 15768770.

30 Sharma AK, Verma K, Khatri S, Kannan AT. Pregnancy in adolescents: a study of risks and outcome in Eastern Nepal. Indian Pediatr. 2001;38(12):1405-9. 